\title{
Laser speckle techniques in quality evaluation of orange fruits
}

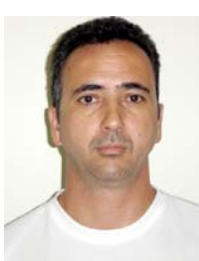

\author{
Giovanni F. Rabelo1, Roberto A. Braga Júnior' ${ }^{1}$ Inácio M. D. Fabbro², \\ Marcelo R. Trivi ${ }^{3}$, Héctor J. Rabal ${ }^{3}$ \& Ricardo Arizaga ${ }^{3}$ \\ ${ }^{1}$ DE/UFLA CP 3037, 37200-000, Lavras, MG. Fone: (35) 3829 1481, E-mail: giovannirabelo@yahoo.com.br (Foto) \\ ${ }^{2}$ FEAGRI/UNICAMP, 13.083-970, Campinas, SP. Fone: (19) 3788 1059, E-mail: inacio@agr.unicamp.br \\ ${ }^{3}$ Centro de Investigaciones Ópticas de La-Plata (CIC-CONICET) \& UID Optimo. Casilla de Correo 124, 1900, La Plata, \\ Argentina. Fone: (54) 221 4712771.E-mail:marcelot@ciop.unlp.edu.br \\ Protocolo 67 - 27/6/2003 - Aprovado em 5/5/2005
}

\begin{abstract}
This work presents a study of a new technology applied in quality tests of oranges. Evaluations were performed using a nondestructive and noninvasive method based on the interpretation of an optical phenomenon that occurs when the fruit is illuminated with coherent light, referred as biospeckle. The speckle patterns of laser light scattered in orange fruits have been measured through their quantification. For the quantification of the variation by biospeckle, the autocorrelation function and the modified occurrence matrix were used. From these functions, two parameters were obtained: the statistical cummulant and the moment of inertia, calculated from the modified occurrence matrix. These values were used as quality and senescence indicators for the specimens and were compared with other parameters, as total soluble solids, total acidity, the penetration force and the storage period. It was observed that the moment of inertia and statistical cummulant decrease during the storage period. Since senescence is dependent on the storage period, it was possible to observe that the measure of the dynamic speckle varies for fruits as their quality decrease, and also the values change with the position where the images are taken.
\end{abstract}

Key words: biological material, senescence, biospeckle

\section{Laser speckle aplicado a avaliação de qualidade de laranjas}

\begin{abstract}
Resumo: Este trabalho apresenta uma nova tecnologia aplicada aos estudos de qualidade de frutos; trata-se de um método não-invasivo e não-destrutivo baseado na interpretação de um fenômeno óptico que ocorre quando o fruto é iluminado por luz coerente, como é o caso do laser, o qual produz um fenômeno de interferência óptica, referido como biospeckle. Os padrões do speckle da luz laser dispersada foram analisados em laranjas, através da quantificação de sua variação temporal. Para quantificar esta variação, utilizaram-se a função autocorrelação e a matriz de ocorrências modificada. Dessas funções, foram obtidos dois parâmetros: os cumulantes estatísticos, calculados a partir da função autocorrelação e o momento de inércia, extraído da matriz de ocorrências modificada. Esses valores foram considerados indicadores de qualidade e de senescência para os espécimes e comparados com o período pós-colheita. Observou-se que o momento de inércia e os cumulantes estatísticos decrescem à medida que aumenta o período de estocagem de laranjas. Uma vez que a senescência depende desse período, é possível se observar que a medida de variação do speckle é diferente para os frutos, conforme baixa sua qualidade e, também que esses valores mudam em função da posição iluminada do fruto.
\end{abstract}

Palavras-chave: material biológico, senescência, biospeckle

\section{INTRODUCTION}

The knowledge of fruit maturity is important for harvesting and post-harvesting process. The literature presents many techniques developed to evaluate the maturity of fruits as well as of any plant organ, based on their mechanical behavior that have been employed to study the mechanical resistance of vegetative tissues in general. These mechanical tests are supported by the classical elastic and viscoelastic laws and principles including failure theories, assuming the basic 
conditions required by the mechanics of continuous media. However, the continuity, isotropicity and homogeneity of vegetative materials by no means matches the characteristics of the ideal material, which generates an uncertainty associated to the real mechanical behavior of the tested samples. The history of the mechanical evaluation of vegetative tissues includes simple compression, stress and strain rates controlled tests, impact test, acoustic tests and lately, optical material behavior based tests. It should be emphasized that the abovereferred uncertainty required new tests to serve as means of comparison and checking of the encountered mechanical properties. The research evolution indicates strong interests in developing tests based upon machine vision and laser instrumentation qualified as non-destructive measuring systems. This paper reports a new alternative for nondestructive tests based on laser techniques, which has been studied and pointed out as a potential application in shelf life prediction of fruits and vegetables. The laser technique consists in studying the temporal variations of the dynamic speckle on oranges. The dynamic speckle phenomenon occurs when laser light is scattered by bodies exhibiting some activity, as the biological material does. The visual appearance of such a phenomenon is similar to a surface of a boiling liquid, originating the denomination of dynamical speckle, boiling speckle or biospeckle. Recent researches based on the identification of the speckle pattern for different biological materials indicate the application of the dynamical speckle in correlation with mechanical properties, seed viability, staining, drying, etc. Despite the complexity of the phenomenon, some approaches have been developed to quantify the temporal variation of the speckle pattern to characterize biological changes. In order to quantify temporal variations of the biospeckle, two approaches are employed: (a) the first one, based on the calculation of the moment of inertia of the cooccurrence matrix of the spatial temporal speckle pattern (STS) and (b) the second one, based on the calculation of the statistical cummulant of the auto-correlation function of the STS. The STS was proposed by Xu et al. (1995). The advantage of using biospeckle characterization, in the study of biological material, relays on the fact that the proposed method is a fast and non-invasive measurement procedure. According to Rabelo (2000), the complexity of the involved phenomena does not permit a simple and reliable approach of a model involving the interaction of light and biological material. The overall objective of this work is to study the biospeckle phenomenon as a measuring procedure of orange quality as it changes during the post-harvest period.

\section{MATERIAL AND METHODS}

Considering $\mathrm{u}$,in Eq. 1, as the random variable representing the intensity level of some region on the image of a biospeckle, for $\mathrm{x}=0, \ldots, \mathrm{L}-1$, the probability density is defined by:

$$
\mathrm{p}_{\mathrm{u}}(\mathrm{x})=\operatorname{Prob}[\mathrm{u}=\mathrm{x}]=\frac{\text { number of pixels with level } \mathrm{x}}{\text { totalnumber of pixels }}
$$

According to Jain (1989), the second order combined probability is useful to obtain the texture of images. This function is defined by Eq. 2, where, $\mathrm{u}_{1}$ and $\mathrm{u}_{2}$ are two successive pixels of the image and $x_{1}$ and $x_{2}$ are the intensity values, respectively.

$$
\mathrm{p}_{\mathrm{u}}\left(\mathrm{x}_{1}, \mathrm{x}_{2}\right)=\mathrm{p}_{\mathrm{u} 1, \mathrm{u} 2}\left(\mathrm{x}_{1}, \mathrm{x}_{2}\right)=\operatorname{Prob}\left[\mathrm{u}_{1}=\mathrm{x}_{1}, \mathrm{u}_{2}=\mathrm{x}_{2}\right]
$$

$\mathrm{p}_{\mathrm{u}}\left(\mathrm{x}_{1}, \mathrm{x}_{2}\right)=$

$=\frac{\text { number of pairs of pixels with levels } \mathrm{u}_{1}=\mathrm{x}_{1}, \mathrm{u}_{2}=\mathrm{x}_{2}}{\text { total }}$

Arizaga et al. (1999), developed a process based on the occurrence of successive intensity values in the whole STS image. The process requires the transformation of the STS in an occurrence matrix, called co-occurrence matrix (COM), defined by Eq. 4, where $\mathrm{N}_{\mathrm{ij}}$ is the number of occurrences of successive intensity values $\mathrm{i}, \mathrm{j}$.

$$
\mathrm{COM}=\left[\mathrm{N}_{\mathrm{ij}}\right]
$$

The entries of the co-occurrence matrix are the number of occurrences of a certain intensity value $i$ followed by an intensity value $\mathrm{j}$, which according to Arizaga et al. (1999) characterizes a particular case of the spatial gray level dependence matrix, employed to characterize the image texture. Figure 1A shows the STS of a low activity sample and its corresponding modified co-occurrence matrix (MCOM). Figure 1B shows the STS of a high activity sample together with its corresponding co-occurrence matrix.

The differences between the two samples mentioned above can be noted by comparing either the STS or the MCOM showed in Figures 1A and B. The nonzero values out of the
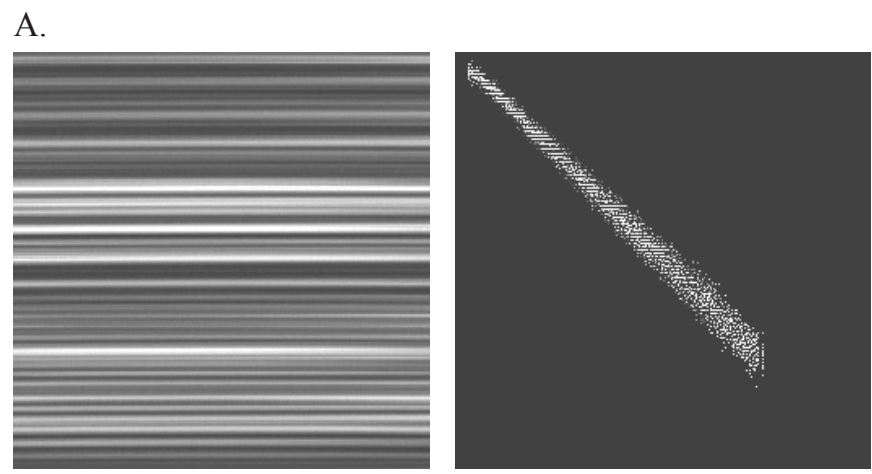

B.
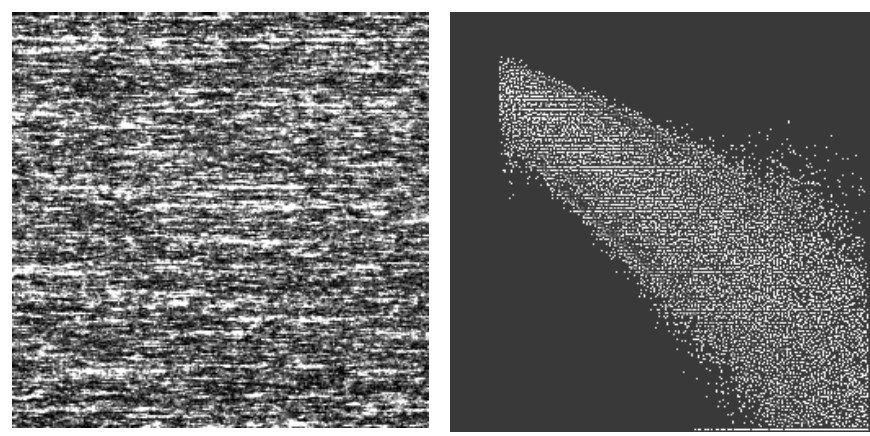

Figure 1. STS \& MCOM of low (A) and high activity sample (B) 
main diagonal indicate changes in intensity of two successive pixels. The dispersion of the points in the matrix indicates the activity level of the biological sample. If the values are concentrated around the main diagonal in the MCOM, the pixels in the STS do not change their intensity value, which means that the sample presents a low activity. The differences between the above Figures have to be quantified, as a measure of the biological activity. The moment of inertia and the statistical cummulant are bio-activity measuring parameters.

The moment of inertia of the co-occurrence matrix is capable of measuring the spread of the $\mathrm{M}$ values around its main diagonal. It is generated by the sum of the matrix values times its squared row distance to the main diagonal, as presented in Eq. 5. This second order moment is then called the moment of inertia of the matrix with respect to its main diagonal.

$$
\mathrm{IM}=\sum_{\mathrm{ij}} \mathrm{M}_{\mathrm{ij}}(\mathrm{i}-\mathrm{j})^{2}
$$

The occurrences in the diagonal do not contribute to increasing the IM value, while far way $\mathrm{M}$ entries add their more heavily weighted values. The method was developed by Arizaga et al. (1999), who carried out several simulations , generating reliable results between 97 and 98\%. The authors observed that when the illumination varied by a factor $\mathrm{c}$, the IM only changed by a factor $\mathrm{c}^{2}$. For comparison purposes, illumination must be kept constant during the measurements.

The statistical cummulant is an approach to obtain the coefficients of a polynomial regression applied to the autocorrelation function of the STS pattern. The auto-correlation function of the STS, $R_{1}(\tau)$, is the average value of the correlation function associated to two successive instantaneous intensity values, as presented in Eq. 6.

$$
\mu=\frac{\left\langle\left(\mathrm{Io}_{\mathrm{o}}-\left\langle\mathrm{I}_{\mathrm{o}}\right\rangle\right)\left(\mathrm{I}_{\mathrm{t}}-\left\langle\mathrm{I}_{\mathrm{t}}\right\rangle\right)\right\rangle}{\sigma_{\mathrm{o} \sigma \mathrm{t}}}=\frac{\frac{1}{\mathrm{~N}} \sum_{\mathrm{i}=1}^{\mathrm{N}}\left(\mathrm{I}_{\mathrm{o}, \mathrm{i}}-\left\langle\mathrm{I}_{\mathrm{o}}\right\rangle\right)\left(\mathrm{I}_{\mathrm{t}, \mathrm{i}}-\left\langle\mathrm{I}_{\mathrm{t}}\right\rangle\right)}{\sigma_{\mathrm{o}} \sigma_{\mathrm{t}}}
$$

where

$$
\sigma_{\mathrm{t}}^{2}=\frac{1}{\mathrm{~N}} \sum_{\mathrm{i}=1}^{\mathrm{N}}\left(\mathrm{I}_{\mathrm{t}, \mathrm{i}}-\left\langle\mathrm{I}_{\mathrm{t}}^{2}\right\rangle\right)
$$

and

$$
\begin{aligned}
\left\langle\mathrm{I}_{\mathrm{t}}\right\rangle & =\frac{1}{\mathrm{~N}} \sum_{\mathrm{i}=1}^{\mathrm{N}}\left(\mathrm{I}_{\mathrm{t}, \mathrm{i}}\right) \\
\mathrm{R}_{1}(\tau \tau & =\langle\mathrm{I}(\mathrm{t}) \mathrm{I}(\mathrm{t}+\tau)\rangle
\end{aligned}
$$

The normalized auto-correlation function may be adjusted by decreasing exponential functions or gaussians. Romero (1999) proposed the use of semi-invariants or statistical cummulant to adjust the auto-correlation function. Initially, it can be considered that the auto-correlation function to behave as a characteristic function, or in another words, the temporal function generates all the statistical moments. According to Pristley (1981), the function that generates the cummulant is defined as the neperian logarithm of the function that generates the moments of a random variable X, as presented in Eq. 10 .

$$
\begin{gathered}
\mathrm{K}(\mathrm{t})=\log _{\mathrm{e}}\{\mathrm{M}(\mathrm{t})\} \\
\mathrm{M}(\mathrm{t})=\mathrm{e}^{\mathrm{K}(\mathrm{t})}
\end{gathered}
$$

If the function $\mathrm{K}(\mathrm{t})$ is expressed in a power series, as in eq. 12 , the coefficients $\left(\mathrm{t}^{\mathrm{r}} / \mathrm{r}\right.$ !) are called the $\mathrm{r}$-th cummulant of the random variable $\mathrm{X}$ (Pristley, 1981).

$$
\mathrm{K}(\mathrm{t})=\mathrm{k}_{1} \mathrm{t}+\mathrm{k}_{2} \frac{\mathrm{t}^{2}}{2 !}+\ldots+\mathrm{k}_{\mathrm{r}} \frac{\mathrm{t}^{\mathrm{r}}}{\mathrm{r} !}+\ldots
$$

But, since $\mathrm{M}(0)=1$, and $\mathrm{K}(0)=0$, there is not constant term in the expansion for $\mathrm{K}(\mathrm{t})$. The cummulant $\mathrm{Kr}$ is related to the moments, and if $\mathrm{M}(\mathrm{t})$ is expanded and compared with the coefficients of the potential $t$, it will be possible to derive the expressions for each cummulant in terms of the moments. In this work the first moments are emphasized. Combining Eqs. 12 and 11, Eq. 13 is obtained, as reported by Romero (1999), who considered that the temporal auto-correlation function behaves statistically as a characteristic function. In Eq. 13, $\mathrm{k}_{\mathrm{n}}$ are the coefficients called semi-invariants or statistical cummulant.

$$
\mathrm{G}^{\prime}(\mathrm{t})=\exp \left[\sum_{1}^{\infty} \frac{\mathrm{k}_{\mathrm{n}}}{\mathrm{n} !}(\mathrm{it})^{\mathrm{n}}\right]
$$

According to Romero (1999) even if it is not secure to consider the auto-correlation as a characteristic function of the light intensity function, the experimental results pointed out that the representation of the Eq. 5 is adequate for describing the auto-correlation function by considering only the first few points. The Eq. 14, used in this work, was used by Rabelo (2000) where the relation between the coefficients $B_{i}$ and the statistical cummulant was given by Eq. 15 .

$$
\begin{gathered}
\mathrm{G}(\tau)=\mathrm{A}+(1-\mathrm{A}) \exp \left\{-\left(\mathrm{B}_{1} \tau+\mathrm{B}_{2} \tau^{2}+\right.\right. \\
\left.\left.\mathrm{B}_{3} \tau^{3}+\cdots+\mathrm{B}_{\mathrm{n}} \tau^{\mathrm{n}}\right)\right\} \\
\mathrm{B}_{\mathrm{i}}=\frac{\mathrm{k}_{\mathrm{i}} \mathrm{i}^{\mathrm{n}}}{\mathrm{n} !}
\end{gathered}
$$

\section{Experimental procedure}

Tests were carried outusing orange fruits harvested in different periods. A $10 \mathrm{~mW}$ helium-neon laser beam with a neutral density filter was used to illuminate the samples and a defocused CCD camera as recording device. The average 
speckle size in the image of the STS resulted in a greater CCD pixel size. The environmental humidity and temperature were kept under control, as proposed by Braga Jr. (2000) and reinforced by Moreira et al. (2003).

A column of speckle pattern image was recorded every 0.08 seconds and a composite image of $512 \times 512$ pixel size was generated by storing consecutive columns digitized to 8 bit gray levels. The co-occurrence matrix and the second order moment were calculated. Average laser illumination was kept constant during the measurements by using a neutral filter for all samples.

All processing steps produced sudden jumps in the intensity due to noise presence in the system which required to discard all entry numbers smaller than 20 in the calculation of the moment of inertia, us propose by Bergkvist (1997). Possible influences of the specular reflections of the sample caused variations of the STS, not taken into account in a first moment, but they were lately considered in a specific test.

The storage period was the most important cause of quality loses in oranges, which were qualified through the biospeckle interpretation.

Four groups of twenty five oranges were selected with similar size and mass at different stages. The samples were exposed to the laser beam during a short period of time and the respective STS were obtained. Informations about the biospeckle time variations were obtained, allowing calculating the moment of inertia of the co-occurrence matrix of the STS and the statistical cummulant applied over the auto-correlation function of the STS. The regression coefficient applied to the auto-correlation function of the STS patterns was also obtained.

Biospeckle images were then collected at four different positions on the fruit surface: two images in diametrically opposite positions on the equator, on the peduncle insertion and on the central calomel base (apex), as shown in Figure 2.

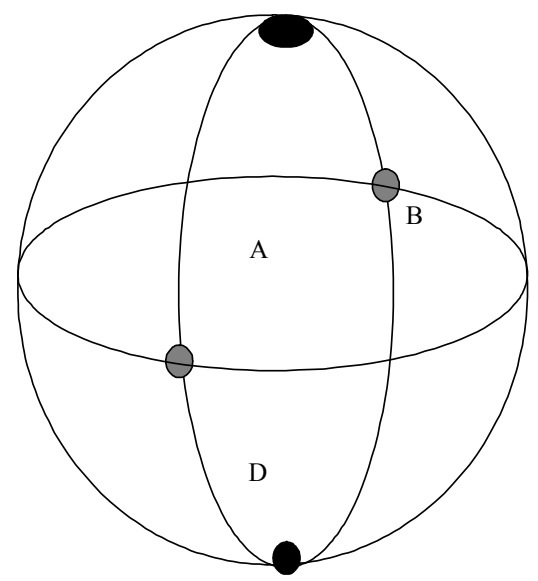

Figure 2. Schematic representation of the positions where images were taken surface of oranges: A, B - equator, C peduncle insertion and $\mathrm{D}$ - apex

\section{RESULTS AND DISCUSSION}

The results of STS carried out on oranges are represented in Figure 3, for one fruit, each diagram is constructed with 512 vertical pixels representing the spatial speckle and 512 horizontal pixels representing the temporal variation of the speckle. These diagrams show that the fruit exhibits a different STS pattern, depending on the illuminated point, which can be observed through the continuity of the lines on it. These diagrams do not permit a precise evaluation through a direct observation. It is necessary to generate numerical values associated to them. These values can be expressed by the statistical cummulant and the moment of inertia, which would be able to distinguish the differences among the fruits. The moment of inertia and the statistical cummulant associated to the images for the four different points on the fruit were calculated. The average values were compared using the SAS program (Statistical Analysis System) through the Tukey test at 5\% significance level. Tables 1 and 2 present the average values of the statistical cummulant and the moment of inertia.
A.

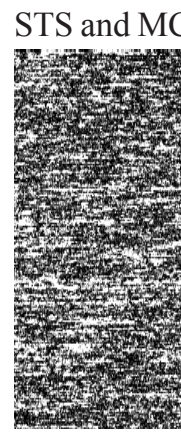

C.
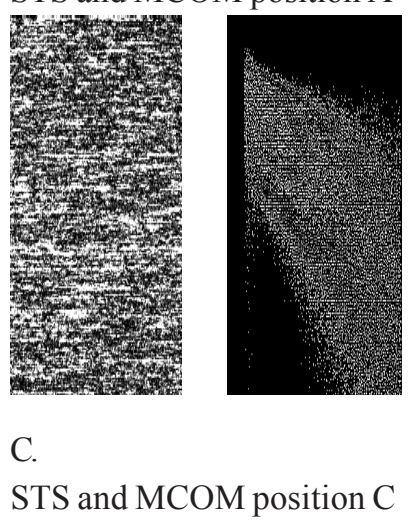

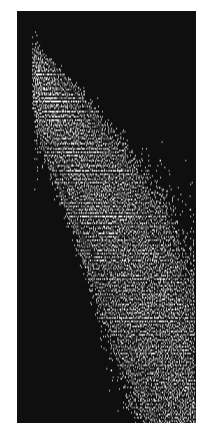

B.

STS and MCOM position B

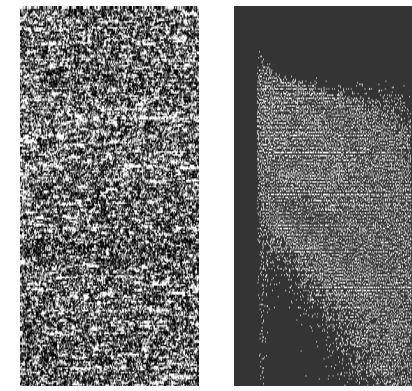

D.

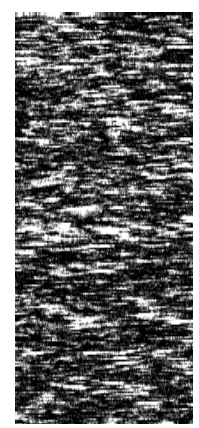

STS and MCOM position D

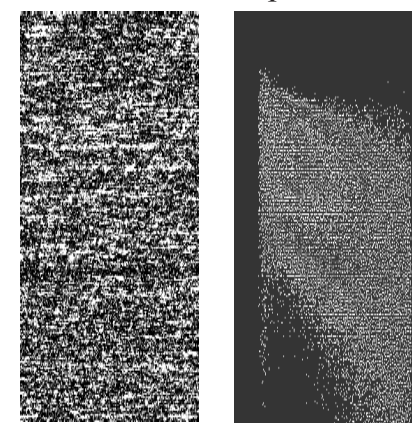

Figure 3. STS and MCOM for images taken on positions: A, B equator, $\mathrm{C}$ - peduncle insertion and $\mathrm{D}$ - apex - (4 days)

Table 1. Tukey grouping of average values for statistical cumulant B1 as a function of the groups for four different positions where image was taken on orange fruits surface

\begin{tabular}{lcccl}
\hline \multicolumn{1}{c}{ Group } & $\begin{array}{c}\text { A } \\
\text { Equator }\end{array}$ & $\begin{array}{c}\text { B } \\
\text { Equator }\end{array}$ & $\begin{array}{c}\text { C } \\
\text { Peduncle Insertion }\end{array}$ & $\begin{array}{c}\text { D } \\
\text { Apex }\end{array}$ \\
\hline I -14 days & $0.137 \mathrm{bc}$ & $0.136 \mathrm{a}$ & $0.077 \mathrm{a}$ & $0.119 \mathrm{c}$ \\
II -7 days & $0.170 \mathrm{ba}$ & $0.164 \mathrm{a}$ & $0.102 \mathrm{a}$ & $0.141 \mathrm{ba}$ \\
III -4 days & $0.131 \mathrm{c}$ & $0.145 \mathrm{a}$ & $0.087 \mathrm{a}$ & $0.131 \mathrm{bc}$ \\
IV -2 days & $0.185 \mathrm{a}$ & $0.174 \mathrm{a}$ & $0.062 \mathrm{a}$ & $0.157 \mathrm{a}$ \\
\hline
\end{tabular}


Table 2. Tukey grouping of average values for moment of inertia as a function of groups for four different positions where image was taken on orange fruit surface

\begin{tabular}{ccccc}
\hline \multicolumn{1}{c}{ Group } & $\begin{array}{c}\text { A } \\
\text { Equator }\end{array}$ & $\begin{array}{c}\text { B } \\
\text { Equator }\end{array}$ & $\begin{array}{c}\text { C } \\
\text { Peduncle Insertion }\end{array}$ & $\begin{array}{c}\mathrm{D} \\
\text { Apex }\end{array}$ \\
\hline I - 14 days & $2632.3 \mathrm{c}$ & $2774.4 \mathrm{~b}$ & $940.0 \mathrm{a}$ & $1861.5 \mathrm{~d}$ \\
II - 7 days & $3329.7 \mathrm{~b}$ & $3255.4 \mathrm{ba}$ & $1673.1 \mathrm{a}$ & $2648.0 \mathrm{c}$ \\
III - 4 days & $4044.7 \mathrm{a}$ & $3932.8 \mathrm{a}$ & $1452.9 \mathrm{a}$ & $3598.7 \mathrm{~b}$ \\
IV - 2 days & $4037.8 \mathrm{a}$ & $4027.7 \mathrm{a}$ & $1250.9 \mathrm{a}$ & $3021.4 \mathrm{a}$ \\
\hline \multicolumn{4}{l}{ (Average values followed by the same letter are not different at 5\% Tukey Test, $\mathrm{p}<0.05)$}
\end{tabular}

Considering the Tukey grouping, for cummulant B1, one can observe that points (B) and (C) do not provide means of differentiation of groups. Point $\mathrm{C}$ presents low activity because it behaves as a scar, where the peduncle is inserted.

Considering the Tukey grouping for the moment of inertia (Table 2), one can observe that the average values for point $\mathrm{C}$ do not present significant differences. Other values for points $\mathrm{A}$ and $\mathrm{B}$ present significant differences. Therefore point $\mathrm{D}$ is the point that allows to identify the activity differences between the stages of the fruits concerning their groups.

Considering the specular reflection, it can be observed that, according to the Tukey grouping, there are no significant differences for the speckle measurement. In this setup, a polarizer was used to eliminate the major part of the specular component of the reflective light. It is supposed that the rays, which are incident on the orange, are reflected, refracted and scattered randomly, leaving the fruit surface in many directions. The specular reflections have great chance of maintaining defined directions, neglecting surface rugosity. Figure 4A shows the STS and MCOM patterns of the biospeckle for the image generated at the position (A) for one specimen of 4 days, including its specular component. Figure 4B shows the

A.
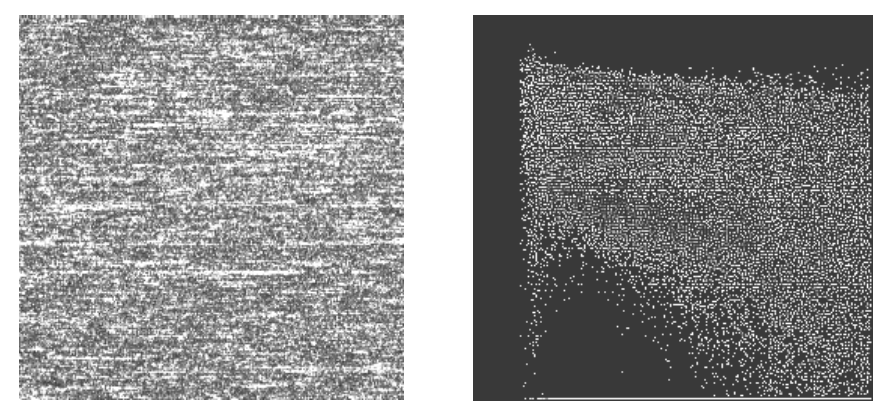

B.
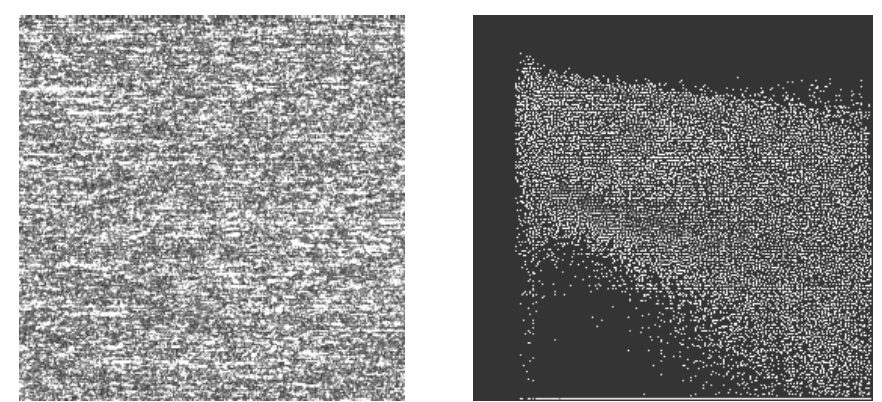

Figure 4. STS \& MCOM for position A, with (A) and (B)without Specular component (4 days)
STS and MCOM of the biospeckle for the image generated at the position (A) for the same specimen without the specular component. The differences between the patterns shown on Figures $4 \mathrm{~A}$ and $\mathrm{B}$ are not easily noted, unless the parameters already known wich as moment of inertia and statistical cummulant. Table 2 shows Tukey grouping for the average values of statistical cummulant for the biospeckle images generated at each of the four points. Table 3 shows Tukey grouping for the average values of the cummulant b1 for the biospeckle images generated at each of the four points. Table 4 shows Tukey grouping for the average values of the moment

Table 3. Average values of the cummulant b1 considering or not the presence of the specular component for each position where image was taken on orange fruit surface

\begin{tabular}{ccccc}
\hline Polarization & $\begin{array}{c}\mathrm{A} \\
\text { Equator }\end{array}$ & $\begin{array}{c}\mathrm{B} \\
\text { Equator }\end{array}$ & $\begin{array}{c}\mathrm{C} \\
\text { Peduncle Insertion }\end{array}$ & $\begin{array}{c}\mathrm{D} \\
\text { Apex }\end{array}$ \\
\hline No & $0,15951 \mathrm{a}$ & $0,15543 \mathrm{a}$ & $0,08415 \mathrm{a}$ & $0,13933 \mathrm{a}$ \\
Yes & $0,15307 \mathrm{a}$ & $0,15503 \mathrm{a}$ & $0,08066 \mathrm{a}$ & $0,13719 \mathrm{a}$ \\
\hline \multicolumn{7}{l}{ Average values followed by the same letter are not different at $5 \%$ Tukey Test, $\mathrm{p}<0.05)$}
\end{tabular}

Table 4. Average values of the moment of inertia with and without the specular component for each position where image was taken on orange fruit surface

\begin{tabular}{ccccc}
\hline Polarization & $\begin{array}{c}\text { A } \\
\text { Equator }\end{array}$ & $\begin{array}{c}\text { B } \\
\text { Equator }\end{array}$ & $\begin{array}{c}\text { C } \\
\text { Peduncle Insertion }\end{array}$ & $\begin{array}{c}\text { D } \\
\text { Apex }\end{array}$ \\
\hline No & 3562,60 a & $3538,90 \mathrm{a}$ & $1393,80 \mathrm{a}$ & $2851,48 \mathrm{a}$ \\
Yes & $3459,60 \mathrm{a}$ & $3456,20 \mathrm{a}$ & $1264,60 \mathrm{a}$ & $2713,31 \mathrm{a}$ \\
\hline \multicolumn{4}{l}{ (Average values followed by the same letter are not different at 5\% Tukey Test, $\mathrm{p}<0.05$ ) }
\end{tabular}

of inertia for the biospeckle images generated at each of the four points.

As one can see, according to the Tukey grouping at 5\% significance level, neither the cummulant nor the moment of inertia are influenced by the specular component, which allows to simplify the setup eliminating the use of polarizers.

\section{CONCLUSIONS}

1. Moment of inertia values and statistical cummulant decrease as the post-harvest period of the orange fruits increases.

2. The measure of the dynamic speckle varies for fruits in different stages.

3. The values of statistical cumulant and the moment of inertia are different.

4. Moment of inertia values and the statistical cummulant do not change with the specular component of the reflected laser light.

\section{ACKNOWLEDGEMENTS}

Thanks to Adriano de Souza for the help in experimental procedures. 


\section{LITERATURE CITED}

Arizaga, R, Trivi, M.R., Rabal, H.J. Speckle time evolution characterization by co-ocurrence matrix analysis. Optics \& Laser Technology, Atlanta, v.4-5, n.3, p.1-7, 1999.

Bergkvist, A. Bisospeckle-based study of the line profile of light scattered in strawberries, Lund Report on Atomic Physics, LRAP-220, Lund, 1997.

Jain, A.K. Fundamentals of digital image processing. Prentice Hall, Inc. Davis: University of California, 1989, 569p.

Moreira, M. F. B. ; Braga Júnior, R. A. ; Borem, F. M. ; Rabelo, G. F. ; Rabal, H. J. ; Trivi, M. R. ; Fabbro, I. M. D. ; Arizaga, R. ; Rodrigues S . Characterization of laser beam Transmission though vegetative material. In: International Congress Information Technology In Agriculture, Food and Environment, 2003, Bornova. Proceedings..., 2003.v.1.p.259-263.
Nascimento, A L.. Utilização do speckle laser para avaliação de qualidade de sêmen de animais domésticos. Lavras:UFLA, 2005. 42p. Dissertação Mestrado

Priestley, M.B. Spectral analysis and time series. San Diego: Academic Press, 6.ed. v.1 e 2, 1981. 890p.

Rabelo, G. F. Avaliação do fenômeno biospeckle" no monitoramento de qualidade de laranjas (Citrus Sinensis). Campinas:UNICAMP, 2000. 147p. Tese Doutorado

Romero, G.G. Estudio y caracterizacion de patrones de speckle que varian en el tiempo. Salta: Facultad de Ciencias Exactas, Departamento de Fisica, Universidad Nacional de Salta, 1999, 133p. Tesis Doctorado

Xu, Z.; Joenathan, C.; Khorana, B.M. Temporal and spatial properties of the time-varying speckles of botanical specimens. Engineering, Atlanta, v.34,n.5, p.1487-1502, 1995. 